\title{
Mitos e fatos nas crônicas da conquista do Antigo Peru
}

\author{
Myths and facts in the chronicles of the conquest of Ancient Peru
}

\author{
Ana Raquel Portugal ${ }^{1}$
}

miauq@hotmail.com

\begin{abstract}
Resumo. As crônicas são fontes históricas de difícil manejo, visto serem uma mescla de mitos e fatos vivenciados por seus autores. Partindo dessa premissa, neste trabalho analisamos algumas dessas fontes espanholas e indígenas sobre a conquista do povo inca e a descrição desse mundo e gente tão distinta. Entre os cronistas escolhidos, destacamos os relatos de José de Acosta sobre o Mundus Novus; os de Cieza de León e Garcilaso de la Vega sobre os mitos dos primeiros chefes incas; por fim, Francisco de Xerez, Juan de Betanzos, entre outros, sobre o evento do aprisionamento e assassinato de Atahualpa, que resultou na conquista do "Tahuantinsuyu" pelos espanhóis.
\end{abstract}

Palavras-chave: mitos, fatos, crônicas.

Abstract. The chronicles of historical sources are difficult because they are a mix of myths and facts experienced by their authors. Starting from this premise, this study analyzes some of the Spanish and indigenous sources on the conquest of the Inca people and the description of this world and people who were so different. Among the chroniclers chosen, the article highlights the reports by José de Acosta on the Mundus Novus and by Cieza de León and Garcilaso de la Vega on the myths of the first Inca chief; finally, Francisco de Xerez,Juan de Betanzos, among others, on the event of the imprisonment and murder of Atahualpa, which resulted in the conquest of the "Tahuantinsuyu" by the Spanish.

Key words: myths, facts, chronicles.

Crónicas: tipo historiográfico de fuerte impronta medieval (recuérdese las crónicas alfonsies), sirvió, sin embargo, para nombrar genéricamente al conjunto de textos objeto de nuestro análisis. El vocablo, al recoger todos los escritos sobre América en el periodo del descubrimiento y colonización, ha experimentado un proceso de ampliación semántica muy importante (Valcárcel Martínez, 1997, p. 22).

As crônicas são uma mescla de história e literatura, de verdade e mentira, de realidade e ficção, e, por isso, sabemos que é um material de difícil manejo, devido a essa fina linha que separa o mundo real do imaginário.

Quando tratamos de rever a história da conquista do Peru à luz de crônicas escritas nos séculos XVI e XVII, não temos a pretensão de utilizá-las 
como provas cabais dos fatos aí relatados. Sabemos que os homens que as redigiram estavam no preâmbulo da Idade Média e Moderna e que possuíam uma série de modelos de respeito às normas locais de autoridade $\mathrm{e}$ às ortodoxias doutrinais, bem como, uma predisposição ao novo e à aventura, própria de uma consciência moderna (Durand, 1953, vol. I, caps. III-VII). Sendo assim, seus escritos eram o resultado de uma mescla de informações culturais. Isso se estende também aos cronistas indígenas e mestiços, visto serem homens que foram alfabetizados e cristianizados pelos espanhóis. Podemos acrescentar ainda que, na relação entre a sociedade indígena e a branca, surgiu a necessidade de resposta diante da conquista e da intenção de imposição de modelos ocidentais, o que se deu através do aparecimento de diversos mitos nativos que incorporaram feitos históricos para recriar a nova realidade sem abandonar a própria cosmovisão. Assim, a produção indígena deve ser analisada para que não fiquemos restritos à visão de história europeia e diferentes tipos de relatos, como mitos e outras formas narrativas podem ser aceitos como amostra de consciência histórica mantida pela memória do grupo através da tradição oral, discursos e outros métodos peculiares a diferentes povos (Hill, 1988).

A alteridade aparece expressa nessas crônicas espanholas quinhentistas, pois retratam o relacionamento do "eu" com o "outro", mostrando primeiro o julgamento de valor que os conquistadores faziam, procurando se aproximar ou distanciar e depois conhecendo ou ignorando por completo a identidade do "outro". Os espanhóis perceberam que a comunicação estava ligada ao poder e que o domínio dos signos autóctones podia propiciar a conquista. Baseados nessa concepção procuraram compreender o "outro", para dominá-lo e depois destruí-lo (Todorov, 1983).

Ao conquistarem o Tahuantinsuyu, não foi diferente. $\mathrm{O}$ espanhol que aí chegou ou desprezou essa nova cultura ou procurou conhecê-la, comparando-a a características familiares, para então dominar essa população. Do relacionamento entre espanhóis e a população local, frutificaram muitas representações culturais expressas em documentos e crônicas desse período.

\section{O Mundus Novus}

quem concluísse que a América era a continuação das Índias orientais.

Las Casas tentou provar isso, argumentando que a fertilidade e felicidade encontrada nesse novo espaço era a mesma que havia na verdadeira Índia, conforme o escrito de antigos historiadores. Ele mencionou que San Isidoro no livro XIV, $3^{\circ}$ capítulo das Etimologias, relatou que a Índia era terra muito fértil, com muita gente, árvores que nunca perdiam as folhas e que davam frutos duas vezes ao ano e que abundava em metais e pedras preciosas, sendo estas as características encontradas no novo continente (Las Casas, 1958, cap. XXII).

Quanto ao povo americano, houve quem dissesse que poderiam ser ofiritas (descendentes do patriarca bíblico Ofir), porém, como os habitantes dessas novas terras não possuíam uma escrita, não guardaram notícias de tais tempos tão remotos (Cabello Valboa, 1951, vol. II, cap. 6).

Acosta refutou essa ideia, principalmente porque, segundo ele, alguns autores afirmaram ser Ofir o mesmo que Peru, visto que na Escritura referiam-se a Ofir como local de onde se trazia ouro finíssimo, pedras muito preciosas e madeira escolhidíssima, igual ao que se encontrou no Peru. Mas, para Acosta, essas eram provas insuficientes para afirmar que o Peru era Ofir, pois, se Salomão tivesse estado em terras peruanas, teria deixado mais evidências (Acosta, 1954, vol. I, cap. XIII).

Tentando explicar esse mundo desconhecido, os cronistas utilizaram toda a sua eloquência para encontrar Atlântida nas terras recém descobertas (López de Gómara, 1918, vol. 1) e relatar a viagem a mando de Salomão a Ofir, que presumidamente seria o antigo Peru (Cabello Valboa, 1951, vol. II, cap. 16). Porém, houve mentes mais sábias, que deixando o mundo mítico de lado, procuraram explicar a presença humana na América de modo mais realista, como o fez Acosta, especialmente no que diz respeito ao Peru. Para ele, essa gente chegou por mar ou por terra, por acaso ou por determinação própria e não através de cavalos com asas, como cogitaram os apreciadores de fábulas (Acosta, 1954, vol. I, cap. XVI).

\section{Mitos genealógicos dos incas}

O mundo incaico possui uma rica mitologia, porém, como seus mitos chegaram a nós por intermédio de crônicas redigidas por espanhóis ou indígenas ladinos ${ }^{2}$, não sabemos até que ponto estes distorceram o discurso pré-hispânico ou realmente esses mitos correspondem a reinterpretações nativas de sua história. de características mentais do medievo europeu conjeturaram sobre o novo espaço territorial encontrado, e houve

2 Índio alfabetizado e cristianizado pelos espanhóis. 
Cieza de León e Ávila relataram ter ouvido dos incas que, em tempos anteriores à sua presença nessa terra, houve um dilúvio que matou quase todos os seres humanos e o mundo esteve em vias de desaparecer. Alguns homens e mulheres se salvaram porque se esconderam em cavernas em montanhas bem altas e, depois que a tormenta passou, saíram e começaram a multiplicar-se, repovoando a terra (Cieza de León, 1991, cap. 3; Ávila, 1966, cap. 3).

Depois disso, como esses homens viviam como feras, sem religião, nem ordem, sem plantar as terras e andavam nus, o Deus Sol se apiedou deles e mandou à terra seu filho e sua filha para que os doutrinassem e os ensinassem a cultivar a terra, criar animais, viver em casas e povoados e lhes predicassem leis para que soubessem viver como homens racionais e não como bestas. Assim, o Deus Sol colocou seus filhos no lago Titicaca e lhes disse para irem por onde quisessem e, onde parassem para comer ou dormir, sempre fincassem no chão a varinha de ouro que levavam com eles. Onde esta vara afundasse de um só golpe, deveriam fundar um novo povoado. Depois de reunir o povo que vivia nas redondezas a serviço do Deus Sol, deveriam mantê-los em ordem e justiça e tratálos sempre com piedade. Os filhos do Sol assim fizeram e no local onde a vara de ouro afundou, criaram Cuzco (Garcilaso de la Vega, 1976, vol. I, cap. XV), cidade que se tornaria a capital do Tahuantinsuyu, que, conforme Gonzalez Holguín (1989, p. 336), foi o nome dado às quatro regiões que formavam o território inca: Antisuyu, Colassuyu, Contisuyu e Chinchasuyu.

Esse é um dos mitos da origem dos incas, que Garcilaso nos contou com grandes pormenores, porém Cieza de León relatou uma versão um pouco diferente. Segundo ele, os homens também viviam em grande desordem, quando saíram de Pacarec Tampu, uma caverna que se localizava próximo a Cuzco, três homens e três mulheres. Os homens que daí saíram se chamavam Ayar Uchu, Ayar Hache Arauca (Ayar Cachi) e Ayar Manco. As mulheres eram Mama Huaco, Mama Cora e Mama Rahua. Saíram vestidos de reis, e um deles tinha uma atiradeira de ouro e uma pedra posta nela. Como era muito forte e com suas pedras derrubava até montanhas, provocou a inveja de seus irmãos, e assim estes convenceram Ayar Cachi a voltar à caverna, onde o encarceraram. Prosseguiram suas andanças sem Ayar Cachi e aonde chegaram fundaram novos povoados (Cieza de León, 1991, cap. VI).

Semelhante a essa história é a outra versão exposta por Garcilaso, que também descreveu os irmãos Ayar como sendo fundadores do Tahuantinsuyu. Este relata que eram quatro homens e quatro mulheres, todos irmãos. Saíram de Paucartampu, e os primeiros irmãos, Manco Capac e Mama Ocllo, fundaram Cuzco, que na língua dos incas significa umbigo. Os incas descenderam desse casal, pois foram eles que subjugaram os povos das nações vizinhas a Cuzco e os ensinaram a ser homens. Garcilaso de La Vega (1976, vol. I, cap. XVIII) questionou a importância dos outros irmãos Ayar, mas não obteve resposta contundente, atribuindo tal resultado ao mundo de fábulas inventadas por esses povos.

O vocabulário cristão encontrado em todos os discursos dos cronistas, espanhóis ou não, por vezes, tende a transformar a história oral incaica numa espécie de catecismo, que, mesclado às noções administrativas espanholas, distorce a realidade social indígena.

Esses discursos espelham a luta de alteridade (Hartog, 1999; Todorov, 1983) vivida nos primeiros tempos de conquista, bem como a incompreensão da sociedade andina por parte dos espanhóis, em que um dos pressupostos principais era a dualidade do governo incaico e que os cronistas tiveram dificuldade em expressar. As únicas alusões ao poder dual são as que aparecem nos mitos dos irmãos Ayar, sucintamente abordados anteriormente e que, conforme os estudos de Rostworowski de Diez Canseco (1988), Duviols (1980, p. 183-196) e Zuidema (1964), comprovam a dualidade do poder incaico.

\section{A dinastia incaica nas crônicas}

Ao tratar dos grandes chefes incas, os cronistas não se eximem de comentários preconceituosos, visto que rebaixar a autoridade destes era uma forma de legitimar o poder espanhol sobre os mesmos. Para Sarmiento de Gamboa (1960, p. 71), os incas foram tiranos que governaram o Peru desde 565 da era cristã até 1533, quando chegaram os espanhóis e implantaram o poder real em nome de Carlos V.

Manco Capac foi o primeiro chefe do Tahuantinsuyu, e Mama Ocllo, sua esposa. Garcilaso nos conta que Manco Capac mandou fundar mais de cem povoados na região do Paucartampu, próxima a Cuzco, e esse foi o início de toda a conquista. Ele não relata a cronologia incaica, pois, ao que parece, nem eles sabiam sobre seu passado ao certo, visto ser uma história antiga demais para ser guardada de memória (Garcilaso de La Vega, 1976, vol. I, cap. XVII ).

É possível supor que, no início da conquista incaica, ainda imperasse o sistema matriarcal, conforme os relatos de Guaman Poma de Ayala. Ele se refere a Mama Huaco como sendo uma mulher muito bonita e feiticeira, que, no começo dos tempos, se casou com seu próprio filho, Manco Capac Inga. Ela falava com as huacas (seres sagrados) e com os demônios, e dela saíram todos os futuros chefes incas. Foi muito amiga do povo e governava mais que o seu marido Manco Capac Inga sobre toda a cidade de Cuzco e jurisdição. Todos lhe 
obedeciam e a respeitavam, pois fazia milagres com a ajuda de demônios (Guaman Poma de Ayala, 1980, p. 121).

Esse relato nos remete a finais do século XVI, período em que se instalou a Inquisição em Lima. Mulheres ditas bruxas começaram a ser perseguidas. $\mathrm{Na}$ verdade, estas não passavam de simples curandeiras, que conheciam plantas medicinais e que, por isso, eram muito respeitadas em suas comunidades. Temendo o poder que estas mulheres possuíam junto aos curacas (chefes locais), os quais sempre recorriam a elas em busca de conselhos, a máquina administrativa da coroa espanhola facultou a perseguição das mesmas, utilizando para tal a Extirpação de Idolatrias. Começaram a aparecer então as histórias normais de um discurso inquisitorial, ou seja, bruxas são as maiores aliadas do diabo e conhecem o poder das plantas para produzir malefícios a outrem (Silverblatt, 1990). A perseguição não se restringiu às mulheres, pois homens também foram acusados de serem dogmatizadores e feiticeiros, pelo mesmo motivo acima afirmado. Guaman Poma, índio ladino, escreveu sua crônica dentro dos modelos religiosos assimilados e de acordo com a realidade que estava vivendo e, por isso, não podia deixar de mencionar o poder do demônio nas mais variadas circunstâncias da história incaica. Ele levou uma vida itinerante e, entre outras coisas, foi auxiliar do Visitador de Idolatrias Cristóbal de Albornoz, com quem aprendeu os códigos culturais europeus.

O discurso do mestiço Garcilaso de la Vega traz à tona uma série de conceitos alheios ao mundo andino, quando este, ao descrever o mandato de Manco Capac, trata em minúcia o momento em que o mesmo resolve apresentar o seu testamento. Manco Capac reinou cerca de 30 anos, não se sabe ao certo. Perto de sua morte, chamou seus filhos, sua esposa Mama Ocllo Huaco e suas esposas secundárias. Encomendou ao príncipe herdeiro e seus demais filhos o amor e benefício para com seus vassalos e aos vassalos a fidelidade e serviço a seu Rei e a guarda das leis que lhes deixava, visto todas serem ordenadas pelo seu pai, o Sol (Garcilaso de la Vega, 1976, vol. I, cap. XXV).

Para Garcilaso, o natural era utilizar vocábulos próprios da realidade espanhola, que tinha por características a vassalagem devida a príncipes e reis, coisa que era distinta entre os incas. Os povos submetidos pelo povo inca não lhe deviam vassalagem, conforme o antigo modelo feudal europeu; na verdade, eram inseridos em um processo de reciprocidade e redistribuição controlado pelos chefes do Tahuantinsuyu.

A genealogia incaica traçada por alguns cronistas não demonstra a dualidade de poder existente, visto que só conheciam o poder monárquico. Por isso, enumeram os Incas dinasticamente, começando por Manco Capac, que foi sucedido por seu filho Sinchi Roca e sucessivamente até Atahualpa. Betanzos (1968) foi um dos cronistas a esboçar uma lista dos Incas, mas nem sequer menciona a Huascar, que no momento da conquista compartilhava o poder com seu irmão Atahualpa. As lutas entre os dois irmãos ficaram amplamente conhecidas (Cieza de León, 1991, cap. LXX, LXXII), sendo um dos argumentos explicativos da derrota incaica diante da pequena quantidade de espanhóis que submeteram Atahualpa e o seu povo em Cajamarca (Las Casas, 1958, cap. CCLXI).

Os cronistas deram por encerrada a história da "dinastia incaica", que governou e doutrinou os povos andinos, a partir do momento em que chegaram os espanhóis. Não compreenderam o sistema político andino, pois era demasiadamente difícil para homens, com mentalidade de fins do medievo, assimilar o novo, o diverso, sem realizar comparações com seus próprios modelos, o que os privou de uma factível interpretação do outro.

\section{Relatos do descobrimento e conquista do antigo Peru}

Hernando Pizarro, Cristobal de Mena, Francisco Xerez, Pedro Sancho de Hoz, Miguel de Estete, Juan Ruiz de Arce, Diego de Trujillo e Pedro Pizarro foram os que primeiro começaram a descrever a conquista do Tahuantinsuyu movidos pelo desejo de eternizar suas memórias idealizadas dessa aventura espanhola. Para aprofundarmos nosso conhecimento sobre as obras que esses soldados nos legaram, é importante entender que tipo de textos produziram, pois, embora possamos incluílos no rol dos Cronistas das Índias, o que eles realmente produziram foram "relaciones", que nada mais são do que o testemunho direto de participantes da conquista. Normalmente, eles relatavam as atividades da expedição em que tomavam parte e se sentiam sérios o suficiente para que fossem dignos de credibilidade. A maioria desses autores escreveu logo após a ação no repouso do acampamento, como o fizeram Francisco de Xerez ou Pedro Cieza de Leon, e também há aqueles que o fizeram já idosos, como foi o caso de Diego de Trujillo (Valcárcel Martínez, 1997, p. 21). Como chama atenção Restall (2006), vários foram os mitos criados pelos cronistas da conquista da América, tanto durante o próprio processo de dominação como posteriormente, de acordo com as descrições encontradas em arquivos e bibliotecas. Entre os principais mitos por ele analisados, podemos destacar a ideia de que sempre um pequeno número de homens era responsável pelo jugo de milhares de nativos, e isso se explica pela necessidade de mostrarem seus feitos ao rei para conseguirem "encomiendas" ou algum tipo de retribuição por seus serviços. 
A primeira relação dos espanhóis depois da conquista foi a de Hernando Pizarro de 1533, que apenas trata do que aconteceu naquele momento no Peru. Francisco de Xerez e Miguel de Estete tratam o episódio vivido em Cajamarca com minuciosos detalhes. Irmão de Francisco Pizarro, Hernando nasceu em Trujillo - Espanha por volta de 1503 e chegou ao Peru em 1532.

Dejados alli los vecinos y repartidos los indios que habia en la comarca del pueblo, se partió con sesenta de caballo e noventa peones, en demanda del pueblo de Caxamalca, que tuvo noticias que estaba en él atabaliba, hijo del Cuzco viejo y hermano del que al presente era señor de la tierra (Pizarro, 1953, p. 51).

Importante relato da conquista, a pequena carta de Hernando Pizarro é uma descrição direta do encontro com Atahualpa, em que este joga a Bíblia (ou Breviário) ao chão, ofendendo os espanhóis, que atacaram e o aprisionaram. Relata ainda a ida até Pachacamac, centro cerimonial localizado ao sul de Lima.

Este pueblo de la mezquita es muy grande e de grandes edificios; la mezquita es grande e de grandes cercados e corrales. Fuera de ella está otro cercado grande, que por una puerta se sirve la mezquita. En este cercado están las casas de las mujeres, que dicen ser mujeres del diablo, e aquí están los silos, donde están guardados los depósitos del oro. Aqui no entra nadie donde estas mujeres están. Hacen sus sacrificios como las que están en las otras casas del sol, por servirse de ellos (Pizarro, 1953, p. 63-64).

Trata-se de relato curto sobre os momentos iniciais da conquista, sendo que nem sequer chega à época em que Atahualpa foi assassinado. Os chefes locais ele chama de caciques e os tem como adoradores de ídolos, mostrando o quanto viviam de forma errada de acordo com a fé cristã.

Em 1534, apareceu em Sevilha um documento intitulado La conquista del Perú, llamada la Nueva Castilla e que durante muito tempo acreditou-se ser de autoria anônima. Só em 1935, Porras Barrenechea provou ser de Cristobal de Mena, um capitão que acompanhara Pizarro em suas aventuras por terras andinas. Mena foi o primeiro a chegar ao Panamá, em 1533, com a notícia da captura de Atahualpa e, em seguida, foi para Sevilha, onde publicou sua crônica. Só meses depois apareceu a crônica de Francisco de Xerez, o secretário de Pizarro. Mena chegou à América entre 1510 e 1513 e participou com Pedrarias Dávila da conquista da Nicarágua. Em 1531, passou a acompanhar Pizarro, mas durante o episódio de Cajamarca ele perdeu poder e preferiu retirar-se e regressar à Espanha. Por ser resultado de um relato espontâneo e ter a primazia entre as demais descrições desse momento histórico, a crônica de Mena é de grande importância, além de procurar ser imparcial e de grande riqueza de detalhes. Ele é o primeiro cronista a referir-se às torturas praticadas pelos espanhóis contra os índios, a descrever o tambor de Atahualpa, que nada mais era que a pele dissecada de seu irmão Huascar, e seu copo fúnebre, lavrado no crânio do mesmo (Mena, 1937, p. 89-97).

Francisco de Xerez nasceu em Sevilha, em 1497, e faleceu em Lima, em 1565. Em 1514, chegou a Terra Firme com Pedrarias Dávila e foi secretário e escrivão de Francisco Pizarro durante as expedições de descobrimento e conquista do Peru. O relato de Xerez é o mais importante de todos que se referem à conquista do Peru e à decadência do Tahuantinsuyu. Como a Relación de Mena foi anterior à de Xerez, este chamou a sua de Verdadera Relación, como se quisesse retificar a de Mena. Fez de suas anotações uma grande obra sobre a epopeia de Pizarro e sua conduta diante dos habitantes das novas terras que conquistava.

Asi en este como en todos los otros que venían de paz mandó el Gobernador pregonar, so graves penas, que ningún daño les fuese hecho en personas ni en bienes, ni les tomasen los mantenimientos más de lo que ellos quisiesen dar para el sostenimiento de los cristianos, castigando y ejecutando las penas en los que lo contrario hacian; porque los naturales traían cada dia cuanto mantenimiento era necesario y yerba para los caballos, y servian en todo lo que les era mandado (Xerez, 1985, p. 77).

Sua crônica tratou ainda da viagem de Tumbez a Cajamarca e da prisão de Atahualpa, sendo esta versão, como a de Pedro Sancho, a palavra oficial de Pizarro sobre o assunto. Tratou da divisão de terras entre os conquistadores sob o comando de Pizarro.

[...] repartió entre las personas que se avecindaron en este pueblo las tierras y solares; porque los vecinos sin ayuda y servicio de los naturales no se podían sostener ni poblarse el pueblo; $y$ sirviendo sin estar repartidos los caciques en personas que los administrasen, los naturales recibirian mucho daño; porque como los españoles tengan conocidos a los indios que tienen en administración, son bien tratados y conservados. A esta causa, con acuerdo del religioso y de los oficiales, que les pareció convenir así al servicio de Dios y bien de los naturales, el Gobernador depositó los caciques y indios en los vecinos deste pueblo, porque los ayudasen a sostener, y los cristianos los doctrinasen en nuestra santa fe, conforme a los mandamientos de sus majestades (Xerez, 1985, p. 81). 
Xerez descreveu a cena de captura de Atahualpa com riqueza de detalhes e mostrou o quanto desprezava o chefe inca, a quem fez fortes críticas.

A Relación de Pedro Sancho de Hoz é um documento importante sobre a conquista do Peru, desde o assassinato de Atahualpa até à fundação da cidade de Lima. Secretário de Francisco Pizarro e sucessor nesta função de Francisco de Xerez, Sancho deu prosseguimento ao relato iniciado por Xerez. Pedro Sancho nasceu em 1514 e parece ter chegado à América por volta de 1530. Não admirava Pizarro, mas seus escritos são de suma importância, visto que correspondem à continuação da obra de Xerez. Quando descreveu Cuzco, forneceu-nos dados sobre a nobreza e seus hábitos de manutenção do poder.

Cada uno de los Señores que ha regido en el pasado, tiene alli su propria casa con todo lo que le fue tributado mientras vivió y ninguno de sus sucesores - que tal es la ley entre ellos-puede, a la muerte de su antecesor, tomar sus bienes como herencia. Asícada Señor tiene su propria vajilla de oro y de plata, sus cosas, su vestimenta y, el que lo sucede, nada de eso puede hacerlo suyo. Los Caciques y Señores muertos mantienen sus casas de recreo, los servicios de sus servidores, sus mujeres; les siembran sus campos de maiz y algo del grano cultivado se lo ponen en sus sepulcros (Sancho de Hoz, 1987, p. 138).

Quando descreveu o povo inca, salientou suas leis e costumes e mencionou as diversas províncias existentes e que paulatinamente passaram ao controle dos espanhóis.

Miguel de Estete nasceu em Santo Domingo de la Calzada, em 1507, e esteve na conquista da Nicarágua quando tinha 25 anos. Acompanhou Pizarro na sua primeira exploração da terra peruana, desde Piura a Cajamarca. Esteve na escolta de Hermando de Soto, que visitou a tenda que o Inca tinha nos arredores dessa cidade, e com os homens de Hernando Pizarro chegou até Pachacamac, cujo famoso templo descreveu. Percorreu, outra vez com Pizarro, Jauja e Cuzco, porém parece que não esteve na fundação desta cidade. Sabe-se que regressou logo à Espanha, porém seus rastros confundem-se com os de outro soldado com o mesmo nome. Morreu em 1550. Sua Relación del viaje que hizo el señor capitán Hernando Pizarro por mandato del Señor Gobernador, su hermano, desde el pueblo de Caxamalca a parama (sic), y de allí a Jauja foi incluída por Francisco de Xerez em sua Verdadera relación... (1534). Sua crônica El descubrimiento y conquista del Perú foi publicada em 1819 (Estete, 1987).

Ruiz de Arce, nascido em Albuquerque, em 1506, saiu de Sevilha e foi para Santo Domingo, Jamaica, Honduras, Nicarágua, Guatemala e, por último, Peru, aonde chegou em 1532. A importância de seu curto relato equipara-se à do de Pedro Pizarro e Diego de Trujillo, visto ser um testemunho presencial do momento da conquista do Peru. Primou pela imparcialidade e pelos detalhes dos hábitos de Atahualpa.

No escupia en el suelo quando gargajaba, o escupia ponia una mujer la mano y en ella escupia, todos los cabellos que se le cayan por el vestido los tomavan las mujeres y los comian, sabido porque hazia aquello el escupir, lo hazia por grandeza, los cabellos lo hazia porque era muy temeroso de hechizos y porque no lo hechizasen los mandaba comer (Ruiz de Arce, 1953, p. 96).

Diego de Trujillo nasceu em Trujillo de Extremadura, em 1505. Em 1530, foi para as Índias com Francisco Pizarro e esteve com ele nas ações em Cajamarca, Cuzco e Jauja. Em 1534, viajou para a Espanha, mas, ao esgotarse sua fortuna, voltou ao Peru (1543). Em sua casa em Cuzco, ofereceu refúgio aos filhos de Atahualpa. Durante as guerras civis, esteve ao lado dos defensores do rei. Em pagamento a esta fidelidade, Francisco de Toledo the outorgou uma encomienda. Morreu em Cuzco. Escreveu Relación del descubimiento del Reyno del Perú, que Porras Barrenechea publicou pela primeira vez em Sevilla, em 1948 (Trujillo, 1985).

Em 1515, nasceu Pedro Pizarro em Toledo. Era primo de Francisco Pizarro e veio com ele para as Índias quando este firmou a capitulación de Toledo (1530). Esteve na fundação de Piura, na expedição a Cajamarca e na consequente captura de Atahualpa. Esteve também entre as hostes que marcharam para Cuzco e defendeu a cidade, junto com Hernando Pizarro, do ataque de Manco Inca. No grupo do conquistador do Peru, lutou contra Almagro em Las Salinas (1538). Ganhou uma encomienda em Tacna e obteve terras e índios em Arequipa, a cuja fundação assistiu. Em troca, a sua posição foi ambígua ante Gonzalo Pizarro, pois, como se negou a respaldar o vice-rei Basco Nuñez Vela, que saiu a atacar o rebelde, esteve a ponto de perder a vida na vitória do vice-rei. Sofreu desterro em Charcas e ali apoiou o pronunciamento de Diego Centeno. Derrotado com este na Batalha de Huarina (1547), fugiu e participou com as forças de La Gasca na batalha de Jaquijahuana (1548). De novo de posse de seus bens em Arequipa, retornou para lá em 1555 e 1571, onde morreu em idade avançada. Em 1571 escreveu a sua Relación del descubrimiento y conquista Del Perú, trabalho que empreendeu por sugestão do vice-rei Toledo e que foi publicado pela primeira vez em Madri, em 1844, sendo um dos mais importantes relatos da conquista, pois conseguiu aliar dados sobre as populações nativas e também sobre o comportamento de seus companheiros em plena ação conquistadora. 
Os relatos dos soldados que acompanharam Pizarro no evento de Cajamarca certamente são de grande importância para conhecermos o que viram, pensaram e sentiram esses homens no momento da conquista. Eles coletaram seus dados junto aos quipucamayoc, homens que eram responsáveis, entre outras coisas, por conservar a história incaica através do quipu, conjunto de cordões coloridos com nós, onde guardavam as memórias do povo e contabilizavam a produção econômica. Porém, essa é a chamada tradição "oficial", da qual absorveram seus dados Cieza de Leon, Cabello Valboa e Martín Murua, por exemplo. Outros recolheram suas informações junto a chefes de diferentes localidades, que lhes contavam suas memórias pessoais, sendo esse o material que originou as Relaciones geográficas de Indias e que também foi utilizado por Sarmiento de Gamboa e Francisco de Toledo. Isso corrobora a ideia de que mesmo as crônicas escritas posteriormente também são de grande valia para esta análise, visto que são importantes fontes etnográficas. Como exemplo disso, temos a obra de Guaman Poma de Ayala, que relatou como Francisco Pizarro e Diego de Almagro, acompanhados de 350 soldados, saíram da Espanha em busca das Índias, bem como de ouro, prata e todas as riquezas que se poderiam encontrar nessas novas paragens. Não tiveram medo, envolvidos que estavam pelo sonho de adquirir ouro e prata (1980, p. 372-374).

Aventurando sus vidas
Han hecho lo no pensado,
Hallar lo nunca hallado,
Ganar tierras no sabidas,
Enriquecer nuestro Estado.
Ganaros tantas partidas
De gentes antes no oidas,
Y también, como se ha visto,
Hacer convertirse a Cristo
Tantas ánimas perdidas (Xerez, 1985, p. 162).

Ao contrário dos espanhóis, os habitantes do Tahuantinsuyu não se regozijaram com a possível chegada desses homens ambiciosos. Antes desse nefasto momento, já os feiticeiros e sacerdotes haviam visto, nas entranhas de animais sacrificados, que coisas terríveis estavam para acontecer. Quando Huayna Capac estava em Quito, recebeu a informação de que havia perto de Tumbez monstros marinhos e homens com barbas, que andavam no mar em grandes casas (Montesinos, 1930, cap. XXVIII).

Houve também quem dissesse que eram viracochas (deuses) tais homens de barbas negras ou ruivas e de belos trajes, que se locomoviam em grandes animais com pés de prata (Titu Cusi Yupanqui, 1916). Certo é que tais homens, deuses ou monstros foram os responsáveis pelo massacre de grande parte da população andina.

O encontro de Pizarro com Atahualpa, em 1532, começou com uma tentativa de reciprocidade, tão conhecida pelos incas, e terminou em guerra. $\mathrm{O}$ motivo para o início da batalha sangrenta, segundo Xerez, foi o fato de Atahualpa ter jogado a bíblia sagrada ao chão. Ofendido, o Frei Vicente Valverde queixou-se a Pizarro, que imediatamente ordenou o ataque. Atahualpa foi prontamente capturado, e o alvoroço foi tremendo; índios correram para todos os lados, fugindo dos tiros e das patas dos cavalos, e outros ficaram paralisados pelo terror. A grande maioria das pessoas que se encontrava na praça de Cajamarca pereceu aí mesmo (Xerez, 1985). Pizarro solicitou um resgate imensurável pela liberdade de Atahualpa e resolveu condená-lo à morte, mesmo depois de ter recebido todo o montante de ouro e prata que havia exigido. Atahualpa, sabendo de sua sentença, rogou a Pizarro por sua vida.

\section{Me maravillo de ti, ob capitán, que, porque habiéndo- me prometido por tu fe y dándote el rescate prometido, no solamente me quitarias las cadenas y me pondrias en libertad, sino que abandonarías mi país, abora, cuando has conseguido el rescate prometido por mi libertad, me has sentenciado a muerte. Si Filippillo te ha dicho que he tramado mataros a los barbudos, no ha dicho la verdad, porque nunca llegué a pensar tal cosa.Te ruego, pues, que me dejes vivir, porque contra ti nunca he pensado ni cometido nada que me haga merecedor de la muerte. Y si no te fías de mí, envíame a España ante el Emperador, a quien of receré gran cantidad de oro y de plata. Si, por el contrario, me matas, te aseguro que mis vasallos eligirán otro Rey que os matará a todos los barbudos. Manteniendome con vida, sin embargo governaré el país en paz y no habrá nadie que se atreva a moverse (Benzoni, 1989, p. 251-252).}

O pedido de Atahualpa não foi levado em conta, pois Pizarro estava resolvido a solucionar todos os seus problemas, pondo fim à vida do Inca. Atahualpa foi retirado da prisão e ao som de trombetas levado para a praça, onde o amarraram a um pau. Enquanto isso, um religioso ia consolando-o e predicando-lhe, por meio de um intérprete, os ensinamentos da fé cristã. Estando ele condenado a morrer na fogueira, nos últimos instantes pediu para ser batizado, a que foi prontamente atendido e, por isso, conseguiu morrer garroteado, livrando-se de ser queimado vivo. Mesmo assim, depois de cumprida a sentença, ainda lhe atiraram fogo à roupa para que 
se queimasse também parte da carne. Seu enterro foi assistido por Pizarro e seus companheiros, com direito a cruz e demais aparatos religiosos cristãos, sendo por fim enterrado numa igreja, como se fosse um verdadeiro espanhol (Sancho de Hoz, 1987).

Esses atos foram criticados por outros espanhóis, como por exemplo, Hernando de Santillán, que reprovou Pizarro e Almagro afirmando que

lo primero que hicieron, fue quitar a los incas su señorio y aun matar al señor principal, que era dicho Atabaliba [por Atabualpa]. Tras esto dieron saco general a la tierra, robando todo cuanto hallaron de oro y plata que estaba en poder de los señores y particulares, y en casas del sol y guacas todo lo más que pudieron haber, de lo cual hicieron las partes que dicen de Caxamalca (Santillán, 1968, p. 120).

Isso não significa que Santillán fosse um defensor dos índios como Las Casas, pois ele concordava com a perpetuidade das encomiendas e fazia duras críticas aos chefes indígenas.

O assassinato de Atahualpa representou um episódio trágico na história do mundo andino, e a conquista espanhola, em termos gerais, demonstrou como a falta de conhecimento do outro pode gerar um desencontro cultural de consequências desastrosas.

A derrota incaica frente a tão poucos espanhóis até hoje é difícil de ser explicada. As descrições do massacre ocorrido em Cajamarca nos mostram a debilidade de milhares de homens diante de alguns cavalos, tiros e coisas aterrorizantes para quem nunca tinha lutado dessa maneira. Por mais que tomemos em conta esses dados, não é possível entender essa indescritível carnificina.

Explicações possíveis para tal tragédia podem estar relacionadas com o fato de os espanhóis não terem atacado desde o princípio, pois fizeram o que era usual para os incas, ou seja, estabeleceram um sistema de reciprocidade, mediante a troca de presentes e mercadorias diversas. Portanto, estabelecido esse sistema e não tendo sido atacados, não haveria por que se prevenir contra os espanhóis; logo, o fator surpresa foi contundente.

Em relação ao momento exato do ataque, em que milhares de índios, atordoados diante do aprisionamento de seu chefe, sucumbiram quase sem reação, somos levado a crer que a verticalidade do poder no Tahuantinsuyu seja um dos fatores de tal reação diante do perigo. Para os incas, o seu chefe era como um deus e, portanto, o responsável por todos os atos e aspirações. Desprovidos de seu deus, esses homens ficaram absolutamente perdidos, visto não estarem acostumados a tomar iniciativas individuais. E, parafraseando Steve J. Stern, os 168 espanhóis que com tanta rapidez derrotaram e capturaram Atahualpa também contaram com muita sorte, pois tal conquista aparentemente fácil logo se transformaria numa tarefa complexa, já que agora eles tinham que aprender a governar o Tahuantinsuyu (Stern, 1986, p. 59).

Embora saibamos que as crônicas nem sempre fornecem dados verossímeis, quando as mesmas histórias são repetidas por distintos homens, podemos crer que tenham algo da realidade vivenciada. Os cronistas do Peru, como todos os outros, colocaram em seus relatos muito de suas paixões pessoais, mas também souberam completar seus dados com as informações coletadas junto aos quipucamayocs, fonte etnológica e antropológica de grande importância, que foi salva do esquecimento por esses homens ávidos por testemunhos de acontecimentos antigos.

\section{Referências}

ACOSTA, J. de. 1954. Historia natural y moral de las Indias. Madrid, Biblioteca de Autores Españoles, 631 p.

ÁVILA, F. de. 1966. Dioses y hombres de Huarochirí. Lima, Instituto de Estudios Peruanos, $278 \mathrm{p}$.

BENZONI, G. 1989. Historia del Nuevo Mundo. Madrid, Alianza Editorial, $350 \mathrm{p}$.

BETANZOS, J. de. 1968. Suma y narración de los Incas. In: F. ESTEVE BARBA, Crónicas peruanas de interés indígena. Madrid, BAE, p. 1-56.

CABELLO VALBOA,M.1951. Miscelánea Antártica. Lima, UNMSM, $561 \mathrm{p}$.

CIEZA DE LEÓN, P. 1991. Crónica del Perú. Lima, PUCP, vol.3, 431 p.

DURAND, J. 1953. La transformación social del conquistador. México, Porrúa y Obregón, 182 p.

DUVIOLS, P. 1980. Algunas reflexiones acerca de las tesis de la estructura dual del poder incaico. Histórica, IV(2):183-196.

ESTETE, M. de. 1987. El descubrimiento y la conquista del Perú. In: A.M. SALAS; M.A. GUÉRIN ; J.L. MOURE (eds.), Crónicas iniciales de la conquista del Perú. Buenos Aires, Editorial Plus Ultra, p. 269-319.

GARCILASO DE LA VEGA, I. 1976. Comentarios reales de los incas. Caracas, Biblioteca Ayacucho, vol. I, 275 p.

GONZALEZ HOLGUIN, D. 1989. Vocabulario de la lengua general de todo el Perú llamada quichua o del Inca. Lima, UNMSM, 707 p.

GUAMAN POMA DE AYALA, F. 1980. Nueva coronica y buen gobierno. Caracas, Biblioteca Ayacucho, vol. I, 429 p.

HARTOG, F. 1999. O espelho de Heródoto: ensaio sobre a representação do outro. Belo Horizonte, Editora UFMG, 474 p.

HILL, J.D. (ed.). 1988. Rethinking history and myth: Indigenous South American perspectives on the past. Urbana/Chicago, University of Illinois Press, $337 \mathrm{p}$.

LAS CASAS, B. de.1958. Apologética historia sumaria. Madrid,BAE, 617 p.

LÓPEZ DE GÓMARA, F. 1918. Historia general de las Indias. In: A. GONZALEZ BARCIA, Historiadores primitivos de Indias. Madrid, BAE, vol. I.

MENA, C. de. 1937. La conquista del Perú llamada la Nueva Castilla. In: R. PORRAS BARRENECHEA, Las relaciones primitivas de la conquista del Perú. Paris, Les Presses Modernes. 
MONTESINOS, F. de. 1930. Memorias antiguas, historiales y politicas del Perú. Lima, Librería y Imprenta Gil, 259 p. (Colección de Libros y Documentos Referentes a la Historia del Perú).

PIZARRO, H. 1953. Carta de Hernando Pizarro a los oidores de la Audiencia de Santo Domingo. In: C. de CANILLEROS, Tres testigos de la conquista del Perú. Buenos Aires, Espasa-Calpe.

ROSTWOROWSKI DE DIEZ CANSECO,M.1988. Estructuras andinas del poder: ideología religiosa y política. $3^{\mathrm{a}}$ ed., Lima,IEP, $197 \mathrm{p}$.

RESTALL, M. 2006. Sete mitos da conquista espanhola. Rio de Janeiro, Civilização Brasileira, 364 p.

RUIZ DE ARCE,J.1953. Advertencias que hizo el fundador del vínculo y mayorazgo a los sucesores en él. In: C. de CANILLEROS, Tres testigos de la conquista del Perú. Buenos Aires, Espasa-Calpe.

SANCHO DE HOZ, P. 1987. La relación de Pero Sancho. Buenos Aires, Editorial Plus Ultra, 328 p.

SANTILLÁN, H. de. 1968. Relación del origen y gobierno de los incas. In: F. ESTEVE BARBA, Crónicas peruanas de interés indígena. Madrid, BAE, p. 97-149.

SARMIENTO DE GAMBOA, P. 1960. Historia Índica. Madrid, BAE, $382 \mathrm{p}$.

SILVERBLATT, I. 1990. Luna, sol y brujas: género y clases en los Andes prehispánicos y coloniales prehispánicos y coloniales. Cuzco, Centro de Estudios Regionales Andinos 'Bartolomé de las Casas', 201 p.
STERN, S.J.1986. Los pueblos indígenas del Peru y el desafio de la conquista española. Madrid, Alianza Editorial, 358 p.

TITU CUSI YUPANQUI. 1916. Relación de la conquista del Perú y hechos del Inca Manco II. Lima, CLDRHP, $151 \mathrm{p}$.

TRUJILLO, D. 1985. Relación del descubrimiento del reino del Perú. Madrid, Historia 16, 207 p.

TODOROV, T. 1983. A conquista da América: a questão do outro. São Paulo, Martins Fontes, 387 p.

VALCÁRCEL MARTÍNEZ, S. 1997. Las Crónicas de Indias como expresión y configuración de la mentalidad renacentista. Granada, Diputación Provincial, 545 p.

XEREZ, F. de. 1985. Verdadera relación de la conquista del Perú. Madrid, Historia 16, 207 p.

ZUIDEMA, R.T.1964. The ceque system of Cuzco: The social organization of the capital of the Inca. Leyden, Brill, $265 \mathrm{p}$.

Submetido em: 04/05/2009

Aceito em: 06/08/2009
Ana Raquel Portugal

UNESP/Franca

Av. Eufrásia Monteiro Petráglia, 900

14409-160, Jardim Dr. Antonio Petráglia

Franca, SP, Brasil 